\title{
Are COVID-19 gastrointestinal symptoms due to oxytocin dysfunction?
}

\author{
Mark Chapman, Senior Biomedical Scientist UHMB, Phuoc-Tan Diep, Consultant Histopathologist \\ UHMB, Manal Atwan, Consultant Histopathologist UHMB
}

\section{INTRODUCTION}

Since 2019 the world's human population has been engulfed by a pandemic caused by the severe acute respiratory syndrome coronavirus 2 (SARS-CoV-2) more commonly referred to as the disease COVID-19. It has been shown to infect a broad spectrum of the population and whilst many demographic groups are asymptomatic or present with mild symptoms, approximately $15 \%$ of infections are severe and a further $5 \%$ critical. ${ }^{1}$ The most common symptoms are generally recognised as being; fever, a new onset continuous cough and a change or loss in taste and smell. In addition to these, several other symptomatic presentations have been reported involving multiple systems including respiratory, dermatological, cardiovascular, hepatic, renal and gastrointestinal (GI). The most common gastrointestinal symptoms are diarrhoea, nausea and vomiting. ${ }^{1}$ This paper will explore the possible links of COVID-19, associated gastrointestinal symptoms and lowered plasma levels of the peptide hormone oxytocin.

\section{COVID-19 AND THE GASTROINTESTINAL SYSTEM}

Within the literature, the incidence of COVID-19 cases presenting with gastrointestinal symptoms varies between $2 \%{ }^{2}$ and $11.6 \% .^{1}$ This figure rises to $49.5 \%$ during hospitalisation cases, which could be aggravated by various drugs including antibiotics. ${ }^{1}$ The same report performed endoscopic guided biopsies in six infected subjects and showed that the virus could be detected throughout the gastrointestinal tract. Other studies ${ }^{3,4}$ have shown that the virus can be detected within the stool of up to $53 \%$ of infected patients. The increasing evidence linking COVID-19 and the gastrointestinal system raises many questions including; what is the mode of infection within the GI tract and how does COVID-19 infection induce gastrointestinal symptoms?

\section{COVID-19 INFECTION OF THE GASTROINTESTINAL SYSTEM}

A pre-requisite of viral infection is the ability to gain entry into host cells. It has been demonstrated that COVID-19 utilises angiotensin converting enzyme-2 (ACE2) as a viral receptor to facilitate this. ${ }^{5}$ Liang et al. utilised RNA sequencing data to demonstrate ACE2 expression in proximal and distal small intestine enterocytes. ${ }^{6}$ Zhang et al. took these findings further by demonstrating that entry into host cells by COVID-19 depends not only on ACE2 but also the transmembrane protease serine 2 (TMPRSS2). ${ }^{7}$ Interestingly the same paper showed that ACE2 expression in absorptive enterocytes from the ileum and colon was higher than that of the lung. Further studies have shown that not only are ACE2 and TMPRSS2 coexpressed in the lung but also within the small intestine and colon. ${ }^{8}$ This evidence suggests a possible oral route of infection through the gastrointestinal system, independent of the lung, assuming that the virus can withstand the harsh acidic transit through the stomach.

\section{OXYTOCIN}

Oxytocin is a nine-amino acid peptide hormone whose ability to induce uterine contractions was discovered as early as 1906. In 1953 Vincent du Vigneaud synthesised oxytocin and in 1955 received a Nobel Prize in chemistry for this work. Over the following few years, with the birth of neuroendocrinology, much of the work relating to oxytocin focused on oxytocin as a female reproductive hormone. Over the last two decades this restricted view of the hormone has expanded with over 27,000 published articles. ${ }^{10}$ Through this research, oxytocin has been found to play a role in a wide and diverse list of conditions. These include psychiatric and behavioural disorders ${ }^{11}$ such as autism spectrum disorders, postpartum depression, anxiety, post-traumatic stress disorders, borderline personality disorder, addiction and pain. Also, oxytocin has protective functions in diabetes, ${ }^{12}$ cardiovascular disease, ${ }^{13}$ cancer ${ }^{14,15}$ and autoimmune ${ }^{16}$ diseases. But what evidence is there that oxytocin may play a role in COVID-19 infections with specific reference to gastrointestinal symptoms?

\section{OXYTOCIN AND COVID-19}

Diep et al. have postulated that lowered oxytocin plasma levels could lead to more severe disease and a worse prognosis to COVID-19 infection. ${ }^{17}$ They came to their conclusions by stepping back and looking for patterns in the literature in those demographic groups that present with more serious disease. Some of the risk factors for morbidity and death of COVID-19 first emerging in China have been shown to be consistent across different countries:

- Young people are less severely affected than the elderly people

- People showing metabolic risk factors are more severely affected than those without

- Females are less severely affected than males

- Pregnant women are not necessarily more vulnerable to the disease than non-pregnant women

- African ethnicity is more of a risk for serious disease than are other ethnic groups such as Caucasians

Within the literature, oxytocin plasma levels have been measured across a range of demographic groups. When compared to the above list some interesting parallels became apparent (see references in Diep et al. ${ }^{17}$ ):

- Higher oxytocin in the young than in the elderly

- Higher oxytocin in metabolically fit individuals compared to those demonstrating metabolic risk factors 
- Higher oxytocin in women than in men

- Higher oxytocin in pregnant women than in nonpregnant women

- Race differences in oxytocin levels have been identified with lower levels in African Americans

Further, infection by COVID-19 could reduce oxytocin function in at least two pathways. Firstly, infection of the hypothalamus could lead to viral cytopathic effects on oxytocin producing neurons, ${ }^{18-20}$ and secondly, oxytocin receptors can be down-regulated by viruses through an mRNA interference mechanism. ${ }^{21}$

In order to postulate further on whether lower oxytocin plasma levels could be responsible for COVID-19 gastrointestinal symptoms and more severe disease presentation, the relationship between oxytocin and the gastrointestinal tract needs to be considered.

\section{OXYTOCIN AND THE GASTROINTESTINAL TRACT}

Monstein et al., in a polymerase chain reaction study demonstrated that both oxytocin and its receptor are expressed throughout the gastrointestinal tract. ${ }^{22}$ The study concluded with "possible physiological and/ or pathophysiological role of OT and OT-receptor expression in the human GI tract and the cellular location of its expression remain to be shown". Welch et al. made great strides in answering these questions in their pivotal paper "Oxytocin regulates gastrointestinal motility, inflammation, macromolecular permeability, and mucosal maintenance in mice". ${ }^{23}$ Using a wide range of experimental techniques, they compared oxytocin receptor knockout mice against wild type mice. As well as identifying that within the gastrointestinal tract the oxytocin receptors are located within enteric neurons and epithelial enterocytes, they also deduced that lower plasma oxytocin levels had the following effects:

- Increased stool mass, water content and transit time

- Decreased gastrointestinal mucosal cell proliferation

- Increased macromolecule intestine permeability

- Decreased villi height and crypt length

- Decreased protection against inflammation

- Decreased mucosal defence against toxins

In short, it appears that oxytocin signalling plays an important role in multiple gastrointestinal functions that are subject to neuronal regulation. It modulates gastrointestinal motility, regulates the proliferation of crypt enterocytes, and mucosal permeability as well as protecting against inflammation. It is not unreasonable to conclude that lower plasma oxytocin levels, as described in those populations most susceptible to more severe COVID-19 infection, may play a part in the onset of gastrointestinal symptoms.

\section{OXYTOCIN AND CMV}

A hypothesis exists in the literature that at least on the surface suggests an alternative explanation as to why some demographic groups are more at risk from COVID-19 infection. It is well known that cytomegalovirus (CMV) infection affects the gastrointestinal tract. ${ }^{24}$ Using a similar thought process as Diep et al., ${ }^{17}$ Moss looked at the groups that are most at risk from severe COVID $-19 .{ }^{25} \mathrm{He}$ suggests that there may be a link between these groups and prior infection with CMV.

We would like to propose that the ideas reviewed in this article are not in opposition to this hypothesis involving CMV. It is well established that herpes viruses share a range of features including a relatively mild primary infection, in most cases, followed by lifelong persistence as a consequence of viral latency and sustained immunological control of viral replication..$^{25}$ This immunological control can be exerted by nitric oxide produced by the vascular endothelium. ${ }^{26}$ Indeed, it has been reported that inherited nitric oxide deficiency can lead to fatal CMV infection. ${ }^{27}$ Of note, oxytocin can induce the production of nitric oxide in endothelium; ${ }^{28}$ therefore, any process that reduces oxytocin levels could lead to a reduction in the ability of the gut's endothelium to exert control over latent CMV. This in turn, could lead to viral reactivation and subsequently to increased inflammation and finally to gastrointestinal pathology and more severe COVID-19 infection. ${ }^{29}$

\section{COULD OXYTOCIN BE USED TO TREAT COVID-19 AND ITS RELATED GI SYMPTOMS?}

Following the arguments set out above we hypothesise that low levels of plasma oxytocin could contribute to the gastrointestinal symptoms produced during COVID-19 infection and normal levels will protect against these. COVID-19 is recognised to exert its effects on multiple bodily systems. Oxytocin receptors can be found throughout the body; its healing and protective effects against COVID-19 may also be multi-systemic. Current findings appear to support this hypothesis with oxytocin being proposed for cardiovascular protection ${ }^{30}$ and for its anti-diabetic properties ${ }^{31}$ in COVID-19. Could raising the plasma levels of oxytocin either prophylactically or after infection act as a treatment for COVID-19? Certainly, oxytocin is readily available, used routinely in labour suites, and considered safe and cheap. All these attributes are certainly attractive.

In the event of oxytocin dysfunction, an exogenous source may help restore normal function. Unfortunately, optimising the efficacy of oxytocin may not be straightforward. The biochemistry of oxytocin is complex; it affects multiple systems and cleaved fragments ${ }^{10}$ have been shown to have activity. In addition, normal endogenous release of oxytocin from the posterior pituitary appears to be pulsatile ${ }^{32,33}$ and overstimulation has the potential to reduce function. ${ }^{34}$ This would be a possibility with prolonged, high dose, non-pulsatile administration such as an intravenous infusion. Fortunately this is unlikely to be the case if intranasal oxytocin or the newer oxytocin dry inhaler is used.

There are however mechanisms for increasing serum oxytocin levels, in a pulsatile manner that do not rely on oxytocin as an exogenous drug and these are freely available. It has been shown that many activities can improve endogenous oxytocin function. These include, 
but are not limited to, yoga,,$^{35}$ intimacy, ${ }^{36}$ massage ${ }^{37}$ and exercise. $^{38}$ In addition, minerals and vitamins such as magnesium, ${ }^{39}$ vitamin $\mathrm{C}^{40}$ and vitamin $\mathrm{D}^{41}$ are vital for its optimal functioning. Even certain probiotic bacteria have been shown to increase oxytocin. ${ }^{42}$

A public education programme to highlight the benefits of oxytocin and how to improve its endogenous function may well prove an effective additional tool in our response to COVID-19. People could be empowered to take control of their own protection against COVID-19 by engaging in endogenous oxytocin optimisation activities. This may also have additional benefits in reducing the rates of chronic conditions such as cardiovascular disease, diabetes, autoimmune disorders and cancer.

\section{Correspondence to:} mark.chapman@mbht.nhs.uk

\section{REFERENCES}

1. Lin L, Jiang X, Zhang Z, et al. Gastrointestinal symptoms of 95 cases with SARS-CoV-2 infection. Gut 2020;69(6):997-1001. Available from: doi: 10.1136/gutjinl-2020-321013

2. Chen N, Zhou M, Dong X, et al. Epidemiological and clinical characteristics of 99 cases of 2019 novel coronavirus pneumonia in Wuhan, China: a descriptive study. Lancet 2020;395(10223):507-13. Available from: doi: 10.1016/S0140-6736(20)30211-7

3. Holshue ML, DeBolt C, Lindquist S, et al. First case of 2019 novel coronavirus in the United States. N Engl J Med 2020;382(10):929-36. Available from: doi: 10.1056/NEJMoa2001191

4. Xiao F, Tang M, Zheng X, Liu Y, LiX, Shan H. Evidence for gastrointestinal infection of SARS-CoV-2. Gastroenterology 2020;158(6):1831-1833.e3. Available from: doi: 10.1053/j.gastro.2020.02.055

5. Wan Y, Shang J, Sun S, et al. Molecular mechanism for antibodydependent enhancement of coronavirus entry. J Virol 2020;94(5). Available from: doi: 10.1128/JVI.02015-19

6. Liang W, Feng Z, Rao S, et al. Diarrhoea may be underestimated: a missing link in 2019 novel coronavirus. Gut 2020 Jun;69(6):1141-3. Available from: doi: 10.1136/gutjnl-2020-320832

7. Zhang H, Kang Z, Gong H, et al. Digestive system is a potential route of COVID-19: an analysis of single-cell coexpression pattern of key proteins in viral entry process. Gut 2020;69(6):1010-1018

8. Hoffmann M, Kleine-Weber H, Schroeder S, et al. SARS-CoV-2 cell entry depends on ACE2 and TMPRSS2 and is blocked by a clinically proven protease inhibitor. Cell 2020;181(2):271-280.e8. Available from: doi: $10.1016 /$ j.cell.2020.02.052

9. Dale HH. On some physiological actions of ergot. J Physiol 1906;34(3):163-206. Available from: doi: 10.1113/jphysiol.1906.sp001148

10. Carter CS, Kenkel WM, MacLean EL, et al. Is Oxytocin "Nature's Medicine"? Pharmacol Rev 2020;72(4):829-61. Available from: doi: 10.1124/pr.120.019398

11. Hurlemann R. Behavioral pharmacology of neuropeptides: oxytocin. 1st ed. New York, NY: Springer Berlin Heidelberg; 2017.

12. Elabd S, Sabry I. Two birds with one stone: possible dual-role of oxytocin in the treatment of diabetes and osteoporosis. Front Endocrinol (Lausanne) 2015;6:121. Available from: doi: 10.3389/fendo.2015.00121

13. Jankowski M, Broderick TL, Gutkowska J. The role of oxytocin in cardiovascular protection. Front Psychol 2020;11:2139. Available from: doi: $10.3389 /$ fpsyg.2020.02139

14. Liu H, Gruber CW, Alewood PF, Möller A, Muttenthaler M. The oxytocin receptor signalling system and breast cancer: a critical review. Oncogene 2020;39(37):5917-5932. Available from: doi: 10.1038/s41388020-01415-8

15. Lerman B, Harricharran T, Ogunwobi OO. Oxytocin and cancer: An emerging link. World J Clin Oncol 2018;9(5):74-82. Available from: doi: 10.5306/wjco.v9.i5.74

16. Li T, Wang P, Wang SC, Wang Y-F. Approaches mediating oxytocin regulation of the immune system. Front Immunol 2017;7:693. Available from: doi: 10.3389/fimmu.2016.00693

17. Diep P-T, Buemann B, Uvnäs-Moberg K. Oxytocin, a possible treatment for COVID-19? Everything to gain, nothing to lose. Clin Neuropsychiatry 2020;17(3):1. Available from: doi: 10.36131/CNEPUB20201703

18. Mussa BM, Srivastava A, Verberne AJM. COVID-19 and neurological impairment: hypothalamic circuits and beyond. Viruses 2021;13(3):498. Available from: doi: 10.3390/v13030498

19. Pascual-Goñi E, Fortea J, Martínez-Domeño A, et al. COVID-19associated ophthalmoparesis and hypothalamic involvement. Neurol -Neuroimmunol Neuroinflamm 2020;7(5):e823. Available from: doi: 10.1212/NXI.0000000000000823
20. Diep P-T. Is there an underlying link between COVID-19, ACE2, oxytocin and vitamin D? Med Hypotheses 2020;110360. Available from: doi: 10.1016/j.mehy.2020.110360

21. Liu Y, Conboy I. Unexpected evolutionarily conserved rapid effects of viral infection on oxytocin receptor and TGF- $\beta / \mathrm{pSmad} 3$. Skelet Muscle 2017;7(1):7. Available from: doi: 10.1186/s13395-017-0125-y

22. Monstein H-J, Grahn N, Truedsson M, Ohlsson B. Oxytocin and oxytocin-receptor mRNA expression in the human gastrointestinal tract: a polymerase chain reaction study. Regul Pept 2004;119(1-2):39_ 44. Available from: doi: 10.1016/j.regpep.2003.12.017

23. Welch MG, Margolis KG, Li Z, Gershon MD. Oxytocin regulates gastrointestinal motility, inflammation, macromolecular permeability, and mucosal maintenance in mice. Am J Physiol Gastrointest Liver Physiol 2014;307(8):G848-62. Available from: doi: 10.1152/ ajpgi.00176.2014

24. You DM, Johnson MD. Cytomegalovirus infection and the gastrointestinal tract. Curr Gastroenterol Rep 2012;14(4):334-42. Available from: doi: 10.1007/s11894-012-0266-4

25. Moss P. "The ancient and the new": is there an interaction between cytomegalovirus and SARS-CoV-2 infection? Immun Ageing 2020;17(1):14, Available from: doi: 10.1186/s12979-020-00185-x

26. Mokry RL, Schumacher ML, Hogg N, Terhune SS. Nitric oxide circumvents virus-mediated metabolic regulation during human cytomegalovirus infection. mBio 2020;11(6): e02630-20. Available from: doi: $10.1128 / \mathrm{mBio} .02630-20$

27. Drutman SB, Mansouri D, Mahdaviani SA, et al. Fatal cytomegalovirus infection in an adult with inherited NOS2 deficiency. N Engl J Med 2020;382(5):437-45. Available from: doi: 10.1056/NEJMoa1910640

28. Thibonnier M, Conarty DM, Preston JA, Plesnicher CL, Dweik RA, Erzurum SC. Human vascular endothelial cells express oxytocin receptors. Endocrinology 1999;140(3):1301-9. Available from: doi: 10.1210/endo.140.3.6546

29. Söderberg-Nauclér C. Does reactivation of cytomegalovirus contribute to severe COVID-19 disease? Immun Ageing 2021;18(1):12. Available from: doi: 10.1186/s12979-021-00218-z

30. Wang SC, Wang Y-F. Cardiovascular protective properties of oxytocin against COVID-19. Life Sci 2021;270:119130. Available from: doi: 10.1016/j.lfs.2021.119130

31. Diep P-T. Oxytocin may be superior to gliptins as a potential treatment for diabetic COVID-19 patients. SciMedicine J. 2021 Jan 16;2:106-7. Available from: doi: 10.28991/SciMedJ-2020-02-SI-10

32. Ueda $T$, Yokoyama $Y$, Irahara $M$, Aono $T$. Influence of psychological stress on suckling-induced pulsatile oxytocin release. Obstet Gynecol 1994;84(2):259-62.

33. Baskaran C, Plessow F, Silva L, et al. Oxytocin secretion is pulsatile in men and is related to social-emotional functioning. Psychoneuroendocrinology 2017;85:28-34. Available from: doi: 10.1016/j.psyneuen.2017.07.486

34. Phaneuf S, Rodriguez Linares B, TambyRaja R, MacKenzie I, Lopez Bernal A. Loss of myometrial oxytocin receptors during oxytocininduced and oxytocin-augmented labour. Reproduction 2000;120(1):917. Available from: doi: 10.1530/jrf.0.1200091

35. Jayaram N, Varambally S, Behere RV, et al. Effect of yoga therapy on plasma oxytocin and facial emotion recognition deficits in patients of schizophrenia. Indian J Psychiatry 2013;55(Suppl 3):S409-413. Available from: doi: 10.4103/0019-5545.116318

36. Carmichael MS, Humbert R, Dixen J, Palmisano G, Greenleaf W, Davidson JM. Plasma oxytocin increases in the human sexual response. J Clin Endocrinol Metab 1987;64(1):27-31. Available from: doi: 10.1210/ jcem-64-1-27

37. Morhenn V, Beavin LE, Zak PJ. Massage increases oxytocin and reduces adrenocorticotropin hormone in humans. Altern Ther Health Med 2012;18(6):11-8.

38. de Jong TR, Menon R, Bludau A, et al. Salivary oxytocin concentrations in response to running, sexual self-stimulation, breastfeeding and the TSST: The Regensburg Oxytocin Challenge (ROC) study. Psychoneuroendocrinology 2015;62:381-8. Available from: doi: 10.1016/j.psyneuen.2015.08.027

39. Antoni FA, Chadio SE. Essential role of magnesium in oxytocin-receptor affinity and ligand specificity. Biochem J 1989;257(2):611-4. Available from: doi: $10.1042 / \mathrm{bj} 2570611$

40. Sheldrick EL, Flint APF. Post-translational processing of oxytocinneurophysin prohormone in the ovine corpus luteum: activity of peptidyl glycine $\alpha$-amidating mono-oxygenase and concentrations of its cofactor, ascorbic acid. J Endocrinol 1989;122(1):313-22. Available from: doi: 10.1677/joe.0.1220313

41. Patrick RP, Ames BN. Vitamin D hormone regulates serotonin synthesis. Part 1: relevance for autism. FASEB J 2014;28(6):2398-413. Available from: doi: 10.1096/fj.13-246546

42. Poutahidis T, Kearney SM, Levkovich T, Microbial symbionts accelerate wound healing via the neuropeptide hormone oxytocin. PLoS ONE 2013;8(10):e78898. Available from: doi: 10.1371/journal.pone.0078898 